\title{
Luchas y defensas escondidas. Pluralismo legal y cultural como una práctica de resistencia creativa en la gestión local del agua en los Andes/
}

\author{
Hidden Struggles and Defences. Legal and cultural pluralism \\ as a creative Resistance Practice in local
} Andean water Management

\section{Rutgerd Boelens}

Universidad de Wageningen, Wageningen, Países Bajos

En los Andes, los derechos de agua se materializan en procesos de lucha social. El artículo examina cómo la lucha por el agua de los colectivos locales no puede comprenderse sin su enraizamiento en subcorrientes dinámicas: los cimientos multicapas, a menudo ocultos, de los derechos de agua. Aquí se entrelazan estrategias comunitarias y fuentes socio-legales plurales. Las subcorrientes alimentan los socio-territorios y las culturas hidráulicas, estableciendo las bases para la defensa de los derechos locales hacia redes político-legales multi-escala. En la práctica, los arreglos y derechos propios a menudo están disfrazados por medio de escudos y estrategias de mimetismo (o imitación), que también permiten hacer uso de los medios de poder dominantes. La creación y la proliferación subsuperficiales de los repertorios sociolegales locales constituyen una importante fuente de defensa contra la usurpación de los derechos de agua y las políticas disciplinarias.

PAlABRAs ClAVE: Gestión de agua; Derechos de agua; Comunidades indígenas; Resistencia; Pluralidad legal; Identidad; Andes.

In the Andes, water rights are enforced in processes of social struggle. This paper explains how water struggles by Andean user collectives cannot be understood aside from their rootedness in dynamic 'undertows': the multi-layered, often concealed water-rights foundations. They entwine plural legal sources and livelihood strategies; there, water rights are shaped materially and discursively. Undertows also constitute the socio-territorial home bases for communities' efforts to upscale their water rights battlegrounds into broader political-legal networks. In practice, this often happens in disguised political forms: through 'mimicry' shields and strategies, which also enable them to shop around in rulers' power factory. Dynamic sub-surface creation and proliferation of water rights repertoires constitute a strong source of defense against encroachment and disciplinary policies.

KEYWORDS: Water management; Water rights; Indigenous communities; Legal pluralism; Identity; Andes 


\section{Introducción}

Dentro de las leyes están las autoridades, está la política, está la plata, la corrupción. Entonces el propietario de la hacienda, dueño de plata, dueño de cosas, dueño de amistades, en ese entonces, tenía hasta al Ministro de Gobierno [...]. Hasta la actualidad, cualquier gestión, cualquier lucha pues, si es que el indio, la organización no se levanta y no protesta, no somos atendidos... (Antonio Laso, presidente de CODOCAL, Licto, Ecuador). ${ }^{1}$

La historia de los países andinos está llena de juegos de poder por parte de las autoridades estatales, las elites locales y las compañías transnacionales para usurpar los territorios locales, así como rechazar y destruir los derechos de agua comunitarios y las reglas de gestión locales. ${ }^{2}$ Pero estos últimos, en variados grados, han resistido ante una incorporación completa a los marcos normativos nacionales y la subordinación a reglas de mercado uniformes. ${ }^{3}$ Tanto las comunidades altoandinas como las áreas urbanas, cada vez más, son testigos de conflictos de agua a gran escala, a veces violentos. Las organizaciones de usuarios locales se enfrentan con compañías de hidroenergía, agrocomerciales, minería, agua potable y de otro tipo, y en las últimas dos décadas las movilizaciones de carácter nacional han desafiado la instalación de nuevos regímenes de políticas privatizadoras. Muchas comunidades campesinas y organizaciones indígenas perciben que las nuevas leyes, planes y políticas de agua, a menudo neoliberales pero también de carácter estatista-paternalista, constituyen otra etapa en los intentos de llevarse recursos que históricamente les pertenecen a ellos y que forman parte de su sustento. En el Perú, Bolivia y el Ecuador ha habido levantamientos masivos nacionales que, en muchas instancias, han resultado efectivamente en una moratoria de la implementación de tales políticas

1 Este artículo se basa en mis investigaciones en los países andinos durante las últimas dos décadas, con diversas organizaciones campesinas e indígenas, instituciones no gubernamentales y estatales, y como coordinador de las redes de investigación de WALIR (Water Law and Indigenous Rights), Concertación y Justicia Hídrica. Se han combinado las metodologías de la investigación-acción y la investigación académica, aplicando la etnografía en combinación con estudios sociotécnicos (entrevistas estructuradas y semiestructuradas, debates grupales, estudio de literatura, mediciones hidrológicas, etc. El documento usa elementos revisados de The Rules of the Game and the Game of the Rules. Normalization and Resistance in Andean Water Control, 2008; y de «Water rights arenas in the Andes: Upscaling the defence networks to localize water control», 2008, 48-65.

2 Castro, julio-diciembre de 2009, 15-22; Crespo Flores, Ibidem, 105-122; Romero Toledo, Romero Aravena y Toledo Olivares, Ibidem, 81-103; Budds, 2010, 197-212.

3 Gelles, 1998, 256-267; Bebbington, Bebbington and Bury, 2010, 307-327. 
hídricas nuevas. ${ }^{4}$ Las protestas se dirigen contra «el modelo» como tal y contra muchos de sus principios y expresiones en particular.

Esta intensa reacción subraya la naturaleza contestataria de los derechos de agua y el hecho de que hay mucho en juego. Aquí es de crucial importancia entender que, a ojos de las comunidades y familias usuarias del agua, la definición real de los derechos de ese preciado líquido no está restringida a las oficinas de abogados, a las propuestas de las agencias gubernamentales o a los escritorios de los ingenieros diseñadores. Al ser la médula del poder del agua, esos derechos son negociados y puestos en vigor en procesos de lucha social.

El elemento central de la lucha por el agua no es sólo el acceso a los recursos hídricos. También la formulación de las reglas (por ejemplo, los contenidos de los derechos y de las reglas de manejo, junto a los mecanismos de adquisición de agua) son claves en el «conflicto por el agua», así como la pregunta ¿quién tiene la autoridad legítima para tomar decisiones y poner en vigor los derechos de agua? Y las luchas por la reforma hídrica subrayan un cuarto elemento fundamental en este campo de batalla: el enfrentamiento por los discursos que establecen, imponen o defienden ciertas políticas de gestión de los recursos hídricos.

Particularmente en el Ecuador y Bolivia — los países de Sudamérica con mayor población indígena- movimientos sociales relativamente bien organizados han sido capaces de cambiar a escala nacional los debates y las constituciones en relación con la reforma de los derechos de agua. La mayoría de las veces, varios actores y plataformas sociales operan unidos y la cuestión de esos derechos se vuelve pública. Éste fue el caso, por ejemplo, de las «guerras del agua» bolivianas y de las masivas movilizaciones nacionales en el Ecuador y el Perú contra los planes neoliberales de privatizar el agua. ${ }^{5}$

Se presta una mayor atención pública (desde la investigación, la política, los medios masivos de comunicación y el activismo global) a aquellos conflictos de agua abiertos que tienen lugar a escala nacional, regional o internacional, a menudo conducidos por un campesinado indígena en alianza con otros movimientos de la sociedad civil. Sus demandas también son más fácilmente entendidas y reconocidas, ya que en gran parte se expresan en el idioma legal y político universal: la mayoría de las ocasiones se dirigen

4 Vos, Boelens y Bustamante, 2006, 37-48; Perreault, 2008, 834-854.

5 Perreault, Idem; Crespo Flores, julio-diciembre de 2009; Bakker, 2009. 
a cambiar instituciones formales y marcos legales y políticos nacionales, o a defender aquellas instituciones y regulaciones que apoyan sus intereses pero que se encuentran amenazadas de reemplazo por la «modernización».

Pero hay un mundo de agua diferente de resistencia y lucha, interrelacionado con el anterior pero mucho más ampliamente distribuido $y$, al mismo tiempo, más raramente advertido. Aún así, probablemente sea mucho más importante su papel en lograr el cambio de las instituciones políticas prevalecientes y en desafiar los grupos de poder que generan esas políticas y moldean las leyes y la racionalidad oficiales. Me refiero a los sistemas locales de gestión de agua y a los marcos normativos cotidianos para regular el agua «desde abajo», que conforman la base de la operación hídrica real en términos técnicos, políticos, culturales y normativos. El hecho de que estas tremendas subcorrientes (que más adelante se conceptualizan como «resacas»), construidas sobre arreglos normativos enraizados e identidades hidráulicas locales, reciban menos atención tiene muchos argumentos: una razón importante es que sus desempeños localizados, los lenguajes y prácticas locales sobre derechos de agua, son ininteligibles y brumosos para los actores externos; también es un factor explicativo la herencia colonial de los prejuicios contra «la atrasada gestión de agua indígena o comunitaria»; además, incluso puede resultar menos interesante para muchos observadores y activistas críticos porque estas comunidades de agua aparentemente aceptan el discurso de progreso universal, acogen sin criticar los conceptos de la modernización y luchan por una formalización de sus derechos de agua.

Pero estas aguas silenciosas llegan a la profundidad. Sin conformarse con aceptar la naturalización de los modelos y políticas de agua dominantes, que disminuirían o destruirían su espacio de maniobra para dar forma a sus propios derechos de agua y formas de gestión, como mostraré, a menudo usan la apariencia de conformidad ante los gobernantes externos, para construir y defender su propia «comunidad de agua». Esto inmediatamente conduce hacia otra razón para su escasa atención pública: es típico que su estrategia evite la acción pública y los campos abiertos de batalla, precisamente para defender su base del desarrollo y la operación de los derechos de agua. Por lo tanto, también se escudan contra la intrusión externa. Con la estrategia de visibilidad intermitente eligen sus propios tiempos, términos y modos de aparecer en el escenario.

Este artículo analiza la contestación de los derechos de agua en los Andes, usando ilustraciones que van desde las luchas abiertas y masivas por el agua hasta las luchas cotidianas para ir contra la normalización externa. 
Examina cómo esas luchas por el agua de los pueblos subordinados en la región andina no pueden ser entendidas sin comprender las maneras en que sus derechos de agua están generados y enraizados en los fundamentos multicapa, a menudo escondidos, de las «comunidades de agua» locales. Aquí, los derechos de agua son estructurados material y discursivamente, constituyendo herramientas funcionales y armas estratégicas. En nuestro trabajo se analiza cómo estos fundamentos dinámicos son una resistencia a mayor escala contra la dominación, comúnmente no a través de confrontaciones abiertas y violentas, sino por medio de estrategias encubiertas: por medio de estrategias de «disfraz» o «mimetismo». Explica cómo las comunidades locales imitan a los grupos de poder, sus estructuras y protocolos. Activamente tratan de generar, usar o expandir sus espacios relativamente autónomos, para defender y materializar sus propios derechos de agua y construir sus contradiscursos y estrategias, que van desde lo físico a lo metafísico. La sección final concluye que, más que solamente la existencia de complejos arreglos de agua, es particularmente la creación continua, dinámica y subsuperficial de los derechos de agua locales y de los repertorios normativos lo que constituye una base fundamental y una fuente de resistencia contra la usurpación de los derechos y las políticas disciplinarias.

\section{De las confrontaciones abiertas a la defensa encubierta de los derechos de agua}

En 1997, dos años antes de que se produjera la Guerra del Agua en Bolivia, que llegó a ser conocida internacionalmente, las comunidades indígenas y campesinas, junto a las municipalidades rurales en el Valle Central de Cochabamba, se involucraron en un grave conflicto cuando la empresa municipal de agua potable empezó a cavar pozos en el Valle Central. Esto afectó severamente a los ya sobreexplotados recursos hídricos. Durante décadas las comunidades habían organizado la distribución del agua de acuerdo con sus usos y costumbres, con sus propias autoridades y marcos sociolegales, y ahora habían determinado que no podían seguir aceptando que otros usurparan los derechos de agua considerados como propios. Cuando el gobierno propuso la privatización de las obras y servicios del agua potable en 1999, los conflictos se volvieron aún más tensos. Tras numerosas protestas de pequeña escala, el Valle Central se volvió un campo de batalla violento en el 2000. Por presiones del Banco Mundial, los gobernantes boli- 
vianos firmaron un contrato con el gran consorcio extranjero Aguas del Tunari, encabezado por la International Water Ltd. (subsidiaria de la Bechtel Corporation de los Estados Unidos), y pusieron en vigor una ley de apoyo a la privatización que permitía a la Compañía tener derechos exclusivos sobre las aguas del distrito, incluyendo aquellas de los sistemas menores en el área metropolitana, y derechos para explotar los acuíferos. Otra ley fue pasada rápidamente por el Parlamento para que la citada Compañía pudiera también captar nuevos recursos hídricos e incluso cobrar tarifas por los pozos comunitarios que iban a ser expropiados. Directamente tras la privatización, la Compañía internacional subió las tarifas de agua, sin mejorar el sistema.

En una fuerte alianza (la Coordinadora del Agua y de la Vida), los usuarios y usuarias urbanos y rurales protestaron en conjunto: los habitantes de la ciudad lo hacían contra el gran aumento en las tarifas de agua, mientras las municipalidades rurales y las comunidades indígenas protestaban contra la nueva ley, porque afectaba a sus derechos y podría exponerlos a nuevas usurpaciones de los recursos hídricos. El conflicto social estalló entre febrero y abril de 2000, con varios días de fuertes encuentros entre los llamados guerreros del agua y la policía, que culminaron en la declaración de un estado de sitio nacional. El gobierno envió miles de soldados bien pertrechados a las calles para romper las protestas y los bloqueos de vías. Un medio de prensa local manifestaba: «Las voces de protesta van en aumento [...] Se denuncia la llegada de aviones provenientes de la ciudad de La Paz, donde se desembarcará una gran cantidad de militares. La ciudad parece estar en guerra, en las calles hay vidrios rotos, llantas quemadas, montones de basura, maderas y piedras en medio de hojas de coca. El pueblo no parece mostrar miedo, se ha puesto de pie y sólo quiere que se le escuche...» (Bolivia Press, 7 de abril del 2000). ${ }^{6}$

Al final de esta Guerra del Agua, que dejó muchas personas muertas y heridas, el gobierno tuvo que retractarse de su decisión y comprometerse también a enmendar la propuesta ley en sus artículos objetados por la alianza popular. La compañía Bechtel tramitó una demanda multimillonaria contra Bolivia en la corte de disputas de inversiones dependiente del Banco Mundial. Tuvieron que pasar cuatro años para que la Bechtel abandonara el caso en enero de 2006, por temor a afectar su imagen pública.

Lo que sucedió en la Guerra del Agua de Cochabamba tuvo un fuerte impacto internacional como ejemplo de resistencia contra la privatización

6 En Peredo, 2003; Bustamante, Peredo y Udaeta. 2005, 72-90. 
del preciado líquido, los servicios de agua y los principios fundamentales de política, y ha sido luego repetido en La Paz y El Alto, donde otro consorcio internacional, Aguas de Illimani, se ha visto forzado a cesar en sus servicios tras años de quejas por parte de los clientes. ${ }^{7} \mathrm{Al}$ mismo tiempo, estas protestas llevaron a la apertura de un proceso de participación más amplio para la formulación de regulaciones y políticas relacionadas con los recursos hídri$\cos$. En la actualidad, con resultados ambivalentes, Bolivia intenta romper la larga herencia dejada por la autoridad colonial, la autoritaria y la neoliberal.

Si bien las Guerras del Agua bolivianas se han vuelto quizás un ejemplo para muchas federaciones de usuarios de agua y para movimientos activistas globales en todo el mundo, la reacción del Ministerio de Información de esa época fue inequívoca: «Estas protestas son una conspiración financiada por el tráfico de coca, que busca pretextos para llevar a cabo actividades subversivas. Es imposible que tantos campesinos se hayan movilizado por sí mismos». ${ }^{8}$ La negación de la capacidad colectiva para protestar y resistirse contra una legislación y un marco de políticas subordinantes es un fenómeno a menudo presente en el mundo de los políticos y hacedores de políticas. Primero, hay una suposición hondamente enraizada de que sólo las propuestas de políticas basadas en «leyes científicas» técnicas y económicas son benéficas porque se aplican de manera universal. Entonces, hay un fuerte escepticismo de que la idea de la resistencia pueda ser una representación colectiva; ya que los miembros de las comunidades andinas son demasiado simples e incapaces de entender los contenidos de estas políticas, los culpables pueden ser únicamente elementos subversivos que manipulan y empujan a una masa campesina e indígena descerebrada.

Pero no es sólo el rechazo de la capacidad mental y organizativa de los colectivos de usuarios, ni la supuesta supremacía de las políticas occidentales-científicas del agua, lo que aparece prominentemente durante tales conflictos de agua. La cuestión de una lucha por la legitimidad de los marcos de derechos sobre este líquido imprescindible está en el núcleo del asunto. El ministro de Información expresó esta cuestión central de manera característica, acusando a la alianza de organizaciones rurales y urbanas y a los que protestaban de desarrollar «una campaña de desinformación diseñada a tumbar la legítima autoridad y el imperio de la ley». ${ }^{9}$

7 Crespo Flores, julio-diciembre de 2009.

8 Fuente: The Associated Press, 11 de abril de 2000 (itálicas añadidas).

9 Comunicado de prensa de la Agencia EFE, 11 de abril de 2000 (itálicas añadidas). 
En efecto, las comunidades indígenas y campesinas tienen muchas razones para desafiar esa legítima autoridad y el imperio de la ley ya que fue precisamente la autoridad del agua de las organizaciones indígenas y campesinas la que fue socavada. Por lo tanto, las luchas contemporáneas por el agua comprenden los siguientes elementos cruciales: acceso al agua y a la infraestructura; reglas y obligaciones relacionadas con la gestión del recurso; la legitimidad de la autoridad para establecer y poner en vigor las reglas y los derechos, y los discursos y las políticas para regular el recurso. En las dos décadas pasadas, como una reacción contra la discriminación étnica, esta lucha por el acceso a los derechos de uso y control del agua ha ido cambiando desde una lucha basada en clases hacia otra cimentada sobre clase y etnicidad («indígena») en especial en países como Bolivia y Ecuador.

En el Ecuador, por ejemplo, a mediados de la década de 1980 surgió el movimiento indígena, y en 1986 la CONAIE fue establecida legalmente como una plataforma amplia. ${ }^{10}$ En 1990 se produjo una movilización masiva y dos años más tarde, nuevamente, miles de indígenas, tras una larga marcha desde la Amazonía hasta la capital, tomaron la ciudad de Quito. Reclamaban el reconocimiento de sus territorios y nacionalidades, con autonomía para hacer las reglas. Desde entonces, el Ecuador no ha podido negar la existencia de una mayoría nacional que desde los primeros tiempos coloniales ha sido rechazada y discriminada, pero que ahora reclamaba su justa proporción y tenía una posición fuerte en el balance de poder a escala nacional. En 1994, tras un gran número de levantamientos, nuevamente el país fue paralizado durante varias semanas por el movimiento indígena. Protestaban resueltamente contra la nueva Ley de Desarrollo Agrario de corte neoliberal, que proponía la privatización de los derechos de aguas y tierras, entre otras cosas. En 1996, tras una amplia consulta y muchos debates desde escalas comunitarias a nacionales, la CONAIE desarrolló su primera propuesta para instalar una nueva Ley de Aguas, ${ }^{11}$ siendo

10 La CONAIE junta a catorce nacionalidades Kichwa y otras catorce nacionalidades indígenas, todas afiliadas a las tres federaciones indígenas actuales: la CONFENIAE (pueblos amazónicos)), la ECUARUNARI (pueblos andinos) y la CONAICCE (pueblos de la costa), lo que crea también una alianza estratégica entre campesinos indígenas y afroecuatorianos. Véase Palacios, 2006, 160-173.

11 La propuesta de la CONAIE incluía demandas para resistir la privatización de los recursos hídricos; control público continuo de la asignación de agua; reconocimiento de los derechos culturales y sociales, y representación de los usuarios y de las organizaciones campesinas e indígenas dentro del marco institucional de la gestión del agua. CONAIE: Propuesta Ley de Aguas, Quito, CONAIE, 1996; Cremers, Ooijevaar y Boelens, 2005, 37-50. 
esta proposición defendida en el Congreso por los primeros diputados del nuevo partido indígena Pachakutik. A pesar de que se aceptó por el desfavorable balance de poderes en el Congreso, la propuesta fue la mecha que encendió un debate continuo sobre la necesidad de una reforma hídrica. Las reglas y los derechos de agua habían llegado a tener un lugar prominente en la agenda nacional. En 1998, la CONAIE y otras plataformas de base y organizaciones campesinas influyeron fuertemente en un proceso de importancia capital: la lucha por una nueva Constitución. Por medio de masivas movilizaciones y debates de carácter nacional, se hizo realidad el proceso de una Asamblea Nacional Constituyente, y la nueva Carta Magna dio mayor reconocimiento a los temas de los derechos colectivos, la pluriculturalidad y las formas de autogobierno, considerados impensables diez años antes. Un fallo importante de la Constitución de 1998, sin embargo, fue su sabor también neoliberal, resultante de las fuerzas opuestas en el país (produciendo el «multiculturalismo neoliberal»). ${ }^{12}$ Diez años después, en 2008, el movimiento indígena, conjuntamente con una alianza de los sectores civiles, y dentro del nuevo panorama político del país liderado por el presidente Correa, fueron capaces de cambiar otra vez la Constitución en una altamente respetuosa de los derechos que reclamaron los grupos indígenas, campesinos y los menos acomodados. En este momento (2011) se enfrentan de nuevo sobre los contenidos y la aprobación de una nueva Ley de Aguas.

Si bien en su fase inicial (1986-1996) el movimiento indígena lucha por la redistribución y el reconocimiento por parte del sistema político externo, entre otros a través de huelgas y movilizaciones masivas, en un segundo periodo (1996-2003), decide unirse no sólo al sistema político, sino al gobierno mismo en los niveles local y nacional, para luchas «desde adentro». ${ }^{13}$ Tras ganar las elecciones de 2002, CONAIE-Pachakutik puso ministros en puestos importantes como Relaciones Exteriores (Nina Pacari) y Agricultura (Luis Macas). Pero inclusive con una importante representación en el Congreso y a todos los niveles en los gobiernos locales, las estructuras de poder dominantes prevalecientes (es decir, las elites oligárquicas y los sectores monopólicos de los negocios neoliberales) tuvieron éxito en frustrar los cambios reales hacia políticas y prácticas de redistribución de agua. Severamente herido y dividido, el movimiento se

12 Assies, 2010, 307-327.

13 Dávalos, 2007. 
separó del gobierno de Gutiérrez en 2003 para recuperarse y, en una tercera fase, reformular sus estrategias, en buena parte nuevamente «contra y desde afuera del sistema». ${ }^{14}$ En la actualidad - época de corte socialista del gobierno de Correa que también trajo importantes avances económicos para muchas comunidades campesinas e indígenas-, el movimiento se opone al nuevo paternalismo hacia los indígenas, la negación de sus federaciones autónomas y el afán gubernativo de controlar los movimientos sociales.

A pesar del hecho de que estas batallas abiertas en el Ecuador y Bolivia, así como las amplias alianzas de carácter nacional (o internacional), constituyen importantes marcadores en la lucha por el reconocimiento y la justicia en los derechos locales (hídricos), e incluso el reclamo de la reconstitución del Estado y su aparato legal, las respectivas estrategias de resistencia han mostrado no ser suficientes como para «remoralizar» la gestión general de los recursos hídricos. En primer lugar, se puede observar que la implementación de los cambios legislativos de la Ley y Reglamentos de Aguas, entre otros, está muy por detrás de las bellas palabras e intenciones en la Constitución. En segundo lugar, y de modo más importante, las leyes no pueden actuar por sí mismas y requieren de fuerzas sociales para materializarse. Con respecto a lo último argumentaré que, más que las grandes «batallas públicas», a menudo con un sabor utópico, es crucial centrarse sobre lo que sucede en los «campos de batalla cotidianos», escenarios comunes de los derechos de agua en el campo. Si bien las guerras de agua de Bolivia han alcanzado los titulares de los principales periódicos en todo el mundo, muchos analistas han sido incapaces de ver que estas guerras, multiplicadas por mil, han estado llevándose a cabo desde hace tiempo, aunque no de manera abierta y violenta como en Cochabamba. En la misma línea, las luchas en el Perú y el Ecuador por la generación local de reglas y la distribución del recurso hídrico no están limitadas a los movimientos sociales a escala nacional, sino que tienen lugar especialmente en las comunidades locales.

Precisamente este gran número de casos locales es el que ha recibido la menor atención en los países andinos e internacionalmente. Incluso los muchos casos de crueldad y banalidad sistematizadas con respecto a la usurpación de los derechos de agua y las injusticias no se han hecho necesariamente asuntos públicos ni han atraído la atención o provocado una

14 Ibidem; Palacios, 2006. 
reacción de parte de la ley o de los políticos. Además de que estos casos localizados merecen más atención por las injusticias de mayor escala cometidas contra los derechos colectivos locales si son vistos en perspectiva acumulativa. También constituyen la base de la resistencia a más amplia escala contra la dominación, por medio de los cambios graduales y continuos que suelen lograr. Más que ser eslóganes de reclamaciones sobre el agua como derecho humano, proveen de la sustancia vital real para las luchas por los derechos hídricos: los contenidos dinámicos y las capas diversas de los derechos de agua, las maneras en que éstos están disputados y dan forma a los contextos legales plurales, y su inserción en las estrategias y las relaciones sociales reales. Además, las luchas de agua más amplias, abiertas y públicas de los pueblos y comunidades subordinadas en la región andina no pueden ser entendidas sin conocer estas batallas locales de bajo perfil. Las primeras no existirían sin las segundas.

Como recalcaré en este artículo, la defensa de los derechos de agua está radicada en el cimiento, usualmente escondido y en múltiples capas, de las «comunidades de agua» donde los derechos son formados material y discursivamente. Aquí, de manera continua, a veces en medio de fuertes contestaciones domésticas sobre la definición y la adquisición de la propiedad hídrica, se crea y consolida una base colectiva. Dentro de esta «comunidad de agua», por razones estratégicas y no románticas o filantrópicas, el foco está sobre un poder colectivo no sólo como un instrumento de dominación (poder-sobre), sino también como una fuerza para protestar y abogar, una fuente de resistencia y creatividad. La capacidad de generar e innovar (poder-para), la acción colectiva organizada (poder-con), y la identificación, identidad y autoestima (poder-dentro),${ }^{15}$ son insumos importantes en los procesos de lucha y empoderamiento de las comunidades locales usuarias del agua. ${ }^{16}$

15 Moffat, Geadah and Stuart, 1991. De manera distinta, también Foucault ha analizado tres de estas formas de poder: poder-sobre, poder-dentro y poder-para. Véase Foucault, 1988 (1982) y Foucault, 1995 (1975).

16 El poder-sobre tiene elementos de poder coercitivo y vertical (como ha sido analizado, por ejemplo, por la tradición Marxista y Weberiana). El poder-con ve el poder como algo que actúa en concierto más que una relación de dominación: resulta de una esfera de intersubjetividad, en la cual hay una acción colectiva que emerge para trabajar hacia alternativas que desafían las relaciones de dominación. El poder-para, a diferencia del poder-sobre, es productivo y creativo. El poder-dentro provee de autoconfianza y es una fuente para la identificación entre los y las colegas que usan el agua, conociendo que son capaces de construir y reforzar sus propios sistemas normativos. 


\section{Derechos locales y pluralismo cultural y normativo}

En las comunidades andinas, las normas de gestión y derechos de agua locales han sido objeto de un proceso permanente de normalización oficial: los grupos de poder siempre han tratado, y siguen tratando, de dominar las normas de gestión locales para mantener u obtener el acceso a este recurso, el control sobre su gestión o sobre la mano de obra, los productos, la conducta y las actividades de los usuarios. ${ }^{17}$ En este proceso de normalización interactúan de manera estratégica y compleja los dominios técnicos, organizativos, sociolegales, político-económicos y metafísicos que constituyen los derechos de agua. Mediante regímenes de representación sutil o brutalmente impuestos, buscan representar los valores, las normas y las prácticas de gestión del agua locales conforme a sus propios intereses.

Pero, de la misma manera, las comunidades andinas, así como grupos subordinados dentro de estas comunidades, tienen sus propias estrategias y proyectos para contrarrestar esta dominación y lograr mayor autonomía. De manera continua y dinámica, construyen sus regímenes específicos de representación. No son proyectos de «restauración de valores, normas y prácticas tradicionales», aunque las normas históricas sí alimentan sus estrategias, sino que en ellos se entretejen muchos elementos contemporáneos para conformar fuertes alianzas entre lo antiguo y lo nuevo, entre lo propio y lo ajeno. Es así que el derecho hídrico local incorpora reglas relacionadas con diversas tradiciones de uso del agua en la región andina y encarna combinaciones particulares de varias fuentes normativas, oficiales y no oficiales. ${ }^{18} \mathrm{Al}$ insertarse en la normatividad local, los elementos de cada una de estas fuentes legales son reinterpretados para ocupar sus espacios relativos en la mezcla localmente dominante que se manifiesta como la gestión local del agua. Como resultado de este panorama de fuentes contemporáneas diversas y de la hibridación de tradiciones de riego, en combinación con las características agroecológicas y físicas de cada ambiente y de la historia particular de subordinación y resistencia sociopolítica, la diversidad de marcos normativos y modalidades de distribución de agua es

17 Gelles, 1998; Guevara, 2006, 126-143.

18 Entre las fuentes sociolegales particularmente importantes en la zona andina están el derecho ancestral y la normatividad religiosa andina (mezclada con la católica), el derecho estatal, el 'derecho de proyecto', y de manera creciente intervienen también las normas mercantiles y el derecho 'del mercado' (Boelens, julio-diciembre de 2009 (2009 $)$, 23-55). 
grande. Aquí tienen un papel muy importante los patrones y los acuerdos organizativos informales y los derechos de agua en acción. Van más allá de las reglas referenciales del Estado y de las asociaciones y derechos formalizados de los mismos usuarios, inclusive cuando se trata de los propios reglamentos comunitarios.

Por eso, una mirada meramente funcionalista-instrumentalista no es suficiente para analizar los derechos de agua en la práctica. Sin desconocer la gran funcionalidad que de hecho tienen los derechos y reglas locales, un enfoque exclusivamente instrumental necesariamente malinterpreta el derecho local. Por ejemplo, a menudo se omiten del análisis los ámbitos culturales y hasta metafísicos del derecho de agua. Esos derechos se vinculan cercanamente con los sistemas culturales de significados, símbolos y valores y, en muchos sistemas, la distribución del agua está profundamente embebida en instituciones y relaciones tanto humanas como sobrenaturales, siendo ambas vistas como elementos que influyen y definen el control del agua. De manera expresa o implícita, la autoridad sobrenatural frecuentemente refuerza la legitimidad de una autoridad y acción humanas; y la movilización de los poderes simbólicos y metafísicos por parte de las comunidades para controlar el agua y regular el comportamiento de sus usuarios puede hacerse tanto de manera inconsciente como con claros propósitos prácticos, por ejemplo, agroproductivos o políticos. Tal funcionalidad a menudo queda fuera de los esquemas de los análisis funcionalistas.

Como observa Greslou, ${ }^{19}$ «es significativo el hecho de que las creencias y costumbres relacionadas con el agua sean las que mejor han sobrevivido a casi cinco siglos de transculturación: estos ritos han mantenido su vigencia, primero porque están ligados a la producción y, en segundo lugar, porque refuerzan la cohesión del grupo social». Yo añadiría, además, que en las comunidades andinas estas creencias y costumbres de agua constituyen a menudo una crítica ideológico-política a las estructuras de poder dominantes. Por un lado, desde épocas pre y poscoloniales, la religión, las cosmovisiones y las metafísicas relativas al agua en los Andes han sido extremadamente funcionales para las clases dominantes en su manipulación y gobierno de las clases subordinadas. Su esfuerzo político era monopolizar los poderes adscritos a las divinidades andinas y cristianas para dominar al pueblo y sus recursos (hídricos), tanto material como ideológicamente, ya que las clases dominantes siempre han entendido el gran poder

19 Greslou, 1989, 6. 
de los ritos y las creencias en los Andes. Por otro lado, y al mismo tiempo, ésta es precisamente la razón de por qué las comunidades locales contestan de forma activa y continúan practicando (y re-desarrollando) sus propios mitos, creencias y metafísicas. Las leyendas, narrativas y creencias de las comunidades usuarias de agua ofrecen un suelo fértil para principios, valores y reglas comunes. Proveen de los antecedentes ideológicos para su «derecho de ser diferente» y para la identificación con sus territorios, fuentes de agua y compañeros usuarios de agua. Como tales, sostienen la acción colectiva para defender o reconquistar estas fuentes, para resistir las intrusiones y reforzar la autonomía de creación de reglas. Las comunidades y pueblos que pierden estos mitos pierden su corazón, particularmente si son mitos de origen, constitución y evolución futura. En muchos de tales casos, las comunidades andinas producen una enorme variedad de estrategias de localización para que retorne el control metafísico.

No es solamente que casi todas las comunidades tienen su propio repertorio religioso, el cual se hibrida con las religiones y cosmovisiones andinas y católicas, entre otras, sino que también reclaman activamente sus fuentes de agua como símbolos de origen y vida. ${ }^{20}$ Un ejemplo, entre muchos, es la forma en que el mito uniforme de la Biblia del Gran Diluvio o el Juicio de Agua, ha sido reinterpretado y reapropiado a través de numerosos mitos locales, explicando el origen, la existencia y las relaciones entre los lagos, las vertientes y las comunidades locales. ${ }^{21} \mathrm{~A}$ este respecto, los poderes dominantes, tanto (pos)coloniales como precoloniales, se ven desafiados. Por ejemplo, los habitantes de la isla Taquile disputan el mito poderoso de los Incas que (para así dominar a las etnias conquistadas) construye metafísicamente el lago Titicaca como el origen del mundo: como Granadino y Jara Jiménez relatan, ${ }^{22}$ estos habitantes reclaman que la Mama Pukyu (Pozo Madre), que pertenece a la Pachamama (Madre Tierra), generó la inundación del planeta y que así surgió el lago Titicaca.

20 Los derechos de propiedad de agua y la identidad constituyen una conexión poderosa desde tiempos históricos. Perreault correctamente analiza que, en la actualidad, la tensión inherente al concepto de 'usos y costumbres' en relación tanto con el enraizamiento histórico-tradicional, como con su naturaleza dinámica contemporánea, hace que el concepto sea a la vez muy complejo, a menudo problemático, e inmensamente poderoso (Perreault, 2008). También Oré elabora la importancia de este nexo de la identidad con el desarrollo del riego (Oré, 2005). Un argumento similar es presentado por Gelles: «El riego estructura los calendarios privados y colectivos de los cabaneños durante una buena parte del año. Da vida a sus campos terraceados y a muchas de sus conversaciones, ... el agua es básica para sus identidades étnicas y comunales» (Gelles, 2000).

21 Cáceres, 2002; Granadino y Jara Jiménez, 1996.

22 Granadino y Jara Jiménez, 1996, 29-31 
La reapropiación y el uso estratégico de normas contestatarias derivadas del control metafísico de agua muestran ser una estrategia poderosa precisamente para los grupos que carecen de poder económico. Por esta misma razón, discrepo con la posición Marxista cuando, en el materialismo histórico, se sostiene que lo metafísico, la religión y la ritualidad, en términos generales, son el «opio del pueblo». Desde luego, como he argumentado, la religión y los poderes adscritos a lo sobrenatural son manipulados, para dominar a las comunidades andinas y los usuarios del agua, tranquilizarlos y evitar su resistencia. Sin embargo, tal posición desconoce la importancia y el poder que pueden representar los mitos, ritos y narrativas locales también para resistir la normalización y la dominación de los grupos e ideologías al mando. Por esta razón, José María Arguedas observaba que, para comprender las luchas por la tierra y el agua en las comunidades andinas, y en especial la intensidad de la defensa de éstas, es necesario penetrar más profundamente en este fundamento cultural, ya que «cuando luchan ...la lucha no es sólo impulsada por el interés económico; otras fuerzas espirituales profundas y violentas enardecen a los bandos...». ${ }^{23}$

\section{«Mimetismo» y espacios normativos propios}

Las expresiones de resistencia, sin embargo, no se dan comúnmente a través de confrontaciones violentas ni movilizaciones a gran escala. Como he discutido, las estrategias ocultas, las acciones encubiertas y las prácticas y espacios políticos codificados son fundamentales como elementos y complementos de las protestas públicas o de las contestaciones masivas. ${ }^{24}$ Aplican «estrategias de visibilidad» alternantes, intermitentes en la esfera pública y en el ámbito comunitario o disfrazado. E incluso cuando se opera en la esfera pública, se hace a menudo con maneras políticas disfrazadas, como la práctica de lo que he llamado mimetismo: el camuflaje detrás de normas y procedimientos formales y de apariencias formalistas; imitando a quienes están en el poder y ratificando en apariencia las reglas dominantes

23 Arguedas, 1977 (1950), 165-174.

24 Véanse también los conceptos de 'transcripciones ocultas', 'discursos tras bastidores' e 'infrapolítica' en Scott, 1990. Pero este mismo autor, en su análisis de la ‘dominación', se limita a los modelos de poder coercitivos. Mi punto es que por eso su análisis no sólo falla en considerar el poder capilar moderno (Foucaultiano) y especialmente sus formas de dominación impersonales y de 'normalización', sino también las correspondientes formas de resistencia. 
pero como una estrategia de resistencia consciente. ${ }^{25}$ Aquí, la apariencia de los formalismos legales que aplicarían las comunidades es muchas veces una ilusión óptica. Así, hay muchas normas y formas de gestión del agua que, a primera vista, parecen estar determinadas por el sistema netamente mercantil o legal oficial pero que, después de un análisis más profundo, demuestran ser lo contrario, y forman parte de la gran fuerza subterránea que enfrenta a los mecanismos de dominación sutiles y disciplinarios.

Un ejemplo es la estructura organizativa que adoptan muchos de los sistemas de uso del agua en la sierra andina, que frecuentemente tiene la estructura formal de los Directorios de Riego, Juntas de Usuarios, Comisiones de Regantes, Comités de Agua Potable u otras estructuras prescritas por las leyes nacionales o por los proyectos de desarrollo. Hasta las formas de representación y los protocolos y procedimientos jerárquicos muchas veces son idénticos a las normas externamente estipuladas, con estatutos legales, documentos legalizados por notarios, etc. ${ }^{26}$ Pero, a pesar de la supuesta homogeneidad y formalidad para fines de la representación externa y la protección formal, bajo esta superficie existe una enorme diversidad organizativa y normativa. Bajo una clara estrategia simuladora yacen, de una manera muy viva y activa, normas y derechos al margen y hasta en contra de la legislación oficial.

Así, aún cuando las estructuras y derechos oficiales parecen haber tenido una influencia normalizadora decisiva, en la práctica las formas organizativas y las normas de gestión y regulación de los recursos hídricos responden a los procesos político-históricos y a los requerimientos sociales y agrofísicos particulares de cada localidad. Y dentro de sus territorios, las comunidades usuarias de agua usan, extienden o pretenden crear activamente estos espacios relativamente autónomos, no patrullados por los poderes dominantes formales, donde materialmente practican sus propios derechos de agua y discursivamente construyen sus contranarrativas. En estos espacios sociales encubiertos y estos «territorios de derechos de agua» ocultos, más allá de solamente estrategias simbólicas hay una confluencia de todos los ámbitos del control del agua (materiales e inmateriales) para defender sus derechos y rechazar la usurpación, la vigilancia y la represión tras bastidores.

25 Boelens, 2009b, 307-331.

26 Éste no es sólo un esfuerzo de codificación y control guiado por el Estado. También es común que las mismas comunidades se ajusten a fórmulas legales para poder obtener acceso legal al agua, así como también para poder optar a préstamos y asistencia pública. 
Paul Gelles, por ejemplo, describe el caso de Cabanaconde, Perú, donde durante la mayor parte del ciclo anual de distribución (es decir, la crucial época seca), la gestión de agua se practica en un escenario social autocontrolado, estando en manos de los alcaldes de Agua (Yaku alcaldes) y de una toma de decisiones colectiva. La Alcaldía de Agua es un cargo político rotativo visto como un tipo de servicio a la comunidad. En Cabanaconde, el alcalde de Agua supervisa los canales, se asegura de que el agua siga un orden establecido y que las tomas sean abiertas y cerradas de manera correcta, y media en los conflictos que puedan aparecer ${ }^{27}$ Los usuarios y usuarias de agua le confieren prestigio, autoridad y especies (coca, alcohol y a veces alimento y pequeñas cantidades de dinero). Ya que el agua de la montaña local es sagrada (no sólo cuida los campos y a los comuneros y comuneras, sino que también puede embrujar, enfermar y cobrarse vidas), el Yaku alcalde debe completar los ritos apropiados para asegurar y mejorar la abundancia de agua, su productividad y el bienestar personal de la gente. Con ese fin emplea técnicas físicas y metafísicas, lo cual también fomenta el avance del agua por los canales de manera oportuna y apropiada. Para que el agua avance rápida y adecuadamente, la comunidad entera observa y participa en estos acontecimientos rituales.

Pero, de acuerdo con Gelles, durante cierto periodo del ciclo de riego (en la época lluviosa), también hay controladores puestos por el Estado que implementan el modelo estatal de «distribución moderna y racional» prescrito por la ley, regando los campos adyacentes de manera secuencial (llamado el sistema «de canto»). Así, rechazan la clasificación dual local de los lotes, que es el patrón que los Yaku alcaldes siguen (el patrón arriba/abajo, o anansaya/urinsaya). No están llevando a cabo ritos elaborados ni patrocinando eventos sociales como los alcaldes de Agua, sino que más bien cumplen una tarea cívica, siendo pagados con dinero y no en especies. Y a pesar de que la gente local está muy consciente de las pérdidas generadas por su propia división de los campos anan/urin, argumenta que el modelo estatal es todavía más ineficiente: «el pago de sueldos por hora no produce ningún incentivo para apurar el agua, y los controladores demoran la entrega para recolectar más dinero en cada lote». ${ }^{28}$ Lo más importante es que, bajo el modelo estatal, las elites locales tienen permiso de usar el sistema para regar los campos adyacentes en orden secuencial

27 Gelles, 1998.

28 Ibidem. 
(de canto) para regar lotes no autorizados, y las decisiones de riego están sujetas a manipulación por parte de individuos poderosos. «Hoy, como desde hace 50 años, ha habido intentos para suplantar completamente el Modelo Local de distribución por el Modelo Estatal. A pesar de que el Modelo Estatal ... ha ganado terreno en los últimos años, el Modelo Local permanece firmemente atrincherado ... Esta adherencia al Modelo Local debe considerarse también como una forma de resistencia a la ideología hegemónica implícita en el propio Modelo Estatal».29

La ley del Perú dicta las maneras en que los usuarios de agua establecidos deben organizarse y pedir las concesiones de derechos de agua. Pero las comunidades andinas desafían activamente el control estatal sobre estas fuentes de agua y, al menos en sus propios espacios y lugares territoriales ocultos, comúnmente se rehúsan a permitir que el Estado determine las prácticas de riego locales. ${ }^{30}$ En estos espacios sociales, los modos locales de organizar cultural y materialmente los derechos y las autoridades del agua encarnan una racionalidad radicalmente diferente a la que se prescribe oficialmente. Y en las comunidades de Cabanaconde, a pesar de que históricamente muchos elementos de la organización dual andina han sido apropiados por los regímenes inca, colonial y hacendario con el objeto de extraer la mano de obra y los recursos de la gente, «los Yaku Alcaldes, un legado de la hegemonía inca y española, hoy día encarnan y ponen en práctica la forma «indígena» de manejo del riego, usada, entre otras cosas, para ritualmente obtener agua, fertilidad y seguridad en abundancia, así como para resistir la interferencia estatal en los asuntos locales». ${ }^{31}$

Claramente, en el marco de las estrategias de resistencia y de los regímenes de re-representación, los derechos de acceso y control de agua son armas de resistencia e instrumentos de autogobierno y autonomía. A diferencia de su papel en las políticas oficiales (donde se presentan como recursos sueltos y independientes y hasta mercantilmente «transferibles»), parte de la fuerza del derecho local de agua está en que se entreteje profundamente con la convivencia comunitaria local. La complejidad del cuadro de los derechos de agua no se restringe sólo a las prácticas de gestión de agua y riego. La asignación y distribución están muy entreveradas dentro de una multitud de instituciones y redes sociales y políticas, algunas de ellas con

29 Ibidem.

30 Boelens and Gelles, 2005, 311-327.

31 Gelles, 1998. 
poca relación con el agua en sí misma. Un ejemplo común es el de la comunidad de Ancoraimes, Bolivia, donde los aportes para ingresar como derechohabiente en el sistema de agua potable no sólo consisten en contribuciones en mano de obra, cuotas y cuestiones administrativas para el sistema hídrico, sino que se refieren al cumplimiento de todos los deberes, es decir, a participar en cargos comunitarios y fiestas culturales y en la organización de actividades cívico-sociales, así como en la participación en las movilizaciones sociales y políticas en defensa del derecho colectivo: las huelgas, los bloqueos y los paros. La no participación en tales actividades de defensa del bien colectivo tiene consecuencias directas en términos de sanciones dentro de la gestión diaria del agua. ${ }^{32}$

Así, los derechos de agua están embebidos en las relaciones históricas, políticas, económicas y culturales que determinan la naturaleza, el valor y la función del agua. Se relacionan estrechamente con la identidad hidráulica de las comunidades usuarias: El embebimiento de los derechos de agua en la comunidad, la dependencia mutua y las obligaciones intrínsecas para una cooperación intensiva entre los usuarios, en contextos adversos de poder y condiciones agrofísicas, refuerzan los nexos de agua culturales y socioterritoriales. La lógica de defensa y reproducción de la «comunidad del agua» en el duro contexto andino, lejos de ser sólo una construcción ideológica, se relaciona con la creación material de una propiedad hidráulica que vincula la acción individual y los derechos de propiedad colectiva.

En este sistema sociotécnico y espacio político-cultural, no sólo el agua, sino también las palabras y las ontologías, reciben una significación distinta de lo universal. Por ejemplo, como acertadamente muestran, ${ }^{33}$ la compra-venta del agua en comunidades bolivianas como las de Luxru Q'achi (Ancoraimes) no se refiere a un concepto netamente mercantil ni a una transacción meramente comercial. Reificado por los abogados del neoliberalismo y su utopismo del mercado libre de agua, y demonizado por las corrientes anticapitalistas que erróneamente sostienen que va en contra de la vida y las costumbres andinas («jel agua es vida y no se vende!»), este acto de compra de agua recibe connotaciones muy particulares y contextualizadas al estar profundamente entretejido con las relaciones locales culturales y sociopolíticas. De ninguna manera recibe el significado de la valo-

32 Laruta, Bustamante et al., 2007.

33 Ibidem. 
rización homogeneizante que los políticos neoliberales quisieran darle, ni la fuerza peligrosa, globalizante y universalista contra la cual advierte la escuela de las políticas macro y radicalistas. En casos como Luxru Q'achi, la comunidad controla las condiciones del proceso de la valorización y de las transacciones, y se asegura de que tengan lugar dentro de los ámbitos económicos, rituales y políticos establecidos por el colectivo, no por el individuo. ${ }^{34}$ Aquellas comunidades que buscan fortalecer su autogestión hídrica no lo hacen para dominar al individuo, sino para asegurar que los anhelos de las familias individuales no impidan el futuro sostenible de la comunidad, una compatibilización mutua que, sin embargo, no se presta a ninguna romantización.

Para reafirmar y ampliar sus derechos de agua y prácticas de sustento internamente y hacia fuera, los colectivos de uso hídrico en los Andes, de manera simbólica y física, sellan campos específicos de relaciones sociales de modo que determinados arreglos son reforzados o ciertos derechos y recursos consolidados. ${ }^{35}$ Por ejemplo, en la mayoría de las comunidades no está permitido vender agua al asignarla fuera del territorio comunitario (lo que infringiría el sistema técnico y normativo), o vender el agua (o tierra regada) a afuereños no miembros de la comunidad. En las comunidades que dependen del riego, más que cualquier otro recurso, el agua es comúnmente vista como el último bastión en la defensa de las relaciones no mercantilizadas. Al formar el núcleo de la continuidad grupal y de las interacciones de casi todas las familias, involucra fuertes normas comunitarias culturales diferentes de muchos otros productos y recursos (por ejemplo, el ganado y la mayoría de cultivos, excepto los alimentos básicos, son vendidos a comerciantes externos). ${ }^{36}$ Por supuesto que estas normas no sólo se refieren a la transferencia del recurso en sí mismo sino al proceso completo de toma de decisiones acerca del recurso colectivo y la reproducción del propio sistema de recursos. Como Long observara correctamente: «se puede argumentar que las instituciones no capitalistas actúan para reestructurar los elementos monetarios introducidos en el sistema, y que con tal de que los campesinos retengan una base relativamente independiente para la operación de sus asuntos económicos, sus relaciones y principios capitalistas no (necesariamente) prevalecerán». ${ }^{37}$

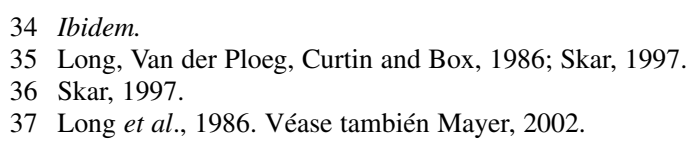




\section{Defensa multiescalar de los derechos de agua}

Hoy día, con la globalización de las relaciones económicas y políticas, es común observar que la gestión del agua, enraizada en la base histórica, política y territorial de la comunidad, cada vez más se ve confrontada con poderosas fuerzas externas e intrusas. También, los adversarios de los colectivos de usuarios locales, como las grandes empresas agro-comerciales, forestales, hidroeléctricas y mineras, así como los políticos y las políticas neoliberales, hacen un uso creciente de nuevos discursos y técnicas globales. Por ello, este proceso va más allá de sólo la expropiación económico-material y se extiende a los campos de los tratados de comercio internacional, los convenios y la legislación internacionales y la comunicación por medios masivos.

Por ejemplo, en el Perú, las acusaciones desde el Estado de ser «terroristas ecológicos» contra aquellos hombres y mujeres que defienden los derechos ambientales y de supervivencia de su comunidad y su hogar, es una nueva táctica de los poderes dominantes ${ }^{38}$ En décadas pasadas, estas acusaciones se hicieron en términos del vocabulario oficial nacional, pero ahora se deriva - tanto en terminología como en cuanto a respuestas y facultades de represión- de la Guerra Internacional contra el Terrorismo (War on Terror). También las prácticas de la inteligencia secreta, las amenazas y los abusos físicos se han intensificado contra quienes reclaman agua, tierra y aire sanos y suficientes en las comunidades peruanas. Al mismo tiempo, de manera intermitente, los entes oficiales y las empresas mineras y forestales que quieren absorber las aguas rurales aplican estrategias de poder «inclusivo y participativo», forzando a que las comunidades y familias individuales se dejan cooptar y se adhieren a los intereses externos: de manera estratégica-política usan el discurso de la necesidad de que las comunidades campesinas e indígenas se incluyan armónicamente en el supuesto «bienestar nacional».

Por estos procesos e impactos de la «glocalización» también las comunidades locales necesitan extender su espacio de maniobrabilidad política y geográfica. ${ }^{39}$ Esto no significa que la estrategia de búsqueda de espacios ocultos y relativamente autónomos analizada antes se abandone. Por el contrario, se considera un fundamento (en muchos aspectos encu-

38 Bebbington et al., 2010.

39 Swyngedouw, 2004, 25-48. 
bierto) que crea las condiciones y la oportunidad para maniobrar hacia campos de batalla externos. Maniobra (que viene del latín manu operare u «operar con las manos»), en sus orígenes significa en concreto «creación manual' y simultáneamente muestra tanto el enraizamiento y el embebimiento en la comunidad (cultivar), como el aspecto de creatividad (manu$r e$ : en inglés, «fertilizar, abonar la tierra»).$^{40}$ En la lucha por la defensa de los derechos la palabra maniobra también posee un significado muy estratégico y práctico: «una acción o movida astuta, frecuentemente evasiva; un cambio de posición para lograr un fin táctico». Y aunque la resistencia no puede ser construida de manera nítida, las maniobras son una acción consciente y cuidadosamente desarrollada: «guiar con destreza y diseño». ${ }^{41}$ Para las comunidades de agua, el espacio para maniobrar se relaciona tanto con la ampliación de la escala geopolítica de ese espacio (el campo de batalla político-legal), como con la defensa y desarrollo de su lugar socio-territorial (comunidad de agua e identidad hidráulica). De esta manera han buscado y tejido nuevas escalas de acción, cada vez más amplias, para fortalecer y consolidar su red de defensa. ${ }^{42}$

\section{Reflexiones}

\section{Los fundamentos multicapa de la comunidad de agua y la interacción político-legal}

Para comprender el pluralismo legal en la gestión hídrica y la naturaleza diversa, dinámica y contradictoria de los sistemas de propiedad común en los Andes, es necesario ir más allá de la dicotomía entre ley oficial y ley consuetudinaria. La gran importancia de los sistemas normativos en los Andes, en combinación con la subvaloración y la opresión que han sufrido durante siglos por parte de las autoridades oficiales y la ley estatal, han llevado a menudo a que se hagan análisis poco críticos y repletos de dogmatismo sobre los contenidos de la ley indígena y campesina. Esto sucede tanto en ciertas visiones que perciben la ley consuetudinaria como una naturaleza muerta de costumbres ancestrales, tradiciones fijas y derechos

40 Webster's: Webster's New Encyclopedic Dictionary, Colonia, Konemann, 1994.

41 Ibidem.

42 Boelens, Getches and Guevara (eds.), 2010. 
históricos absolutos, como en las corrientes que idealizan la armonía de la vida andina y los sistemas comunitarios. Tales análisis de la ley consuetudinaria omiten sus contradicciones internas o la colocan en un pedestal esencialista. Sin embargo, una definición local de derechos equitativos no se refiere a un concepto de armonía, o a dogmas campesinos o indígenas, sino a una construcción política dinámica que refleja los objetivos divergentes - económicos, institucionales y culturales - y el poder de los grupos de la sociedad involucrados. Estos grupos, tanto internos como externos, debaten y negocian las reglas en los encuentros y escenarios cotidianos donde tiene lugar el desarrollo de sus sistemas de riego. Para los usuarios de agua campesinos e indígenas, estos procesos dinámicos toman la tradición no como un factor determinante sino como una fuente de normas contemporáneas, como insumos para poner carne a los derechos actuales.

Los colectivos de control del agua son instituciones de hombres y mujeres usuarios de agua internamente diferenciadas, entidades multicapa cuyos miembros están diferenciados por los derechos de propiedad, el género, el estatus y, frecuentemente, la etnia. Al mismo tiempo, están unidas por una dependencia mutua para desarrollar, usar y gestionar sus recursos hídricos, por un sentido de identidad hidráulica colectiva, y están determinados a concretar su interdependencia y materializar sus derechos de agua colectivos e individuales al involucrarse en estrategias de acción colectiva. Los derechos de agua, son, en efecto, contestados tanto entre esos usuarios, como frente a terceros. Pero dentro del territorio y los espacios sociales del sistema, en caso de conflictos, hay un gran interés colectivo en su resolución tan bien y tan pronto como sea posible, para restaurar una cooperación efectiva. El desarrollo de reglas, invariablemente con conflictos, no se contradice con el hecho de que haya intereses fundamentales comunes compartidos por las familias usuarias en los sistemas comunitarios andinos. Esta reciprocidad contractual colectiva es enteramente diferente a los arreglos contractuales de tipo mercantil y se construye sobre la confianza, la moral comunitaria y la cohesión social a largo plazo. Con base en una cultura, una historia y unas estrategias de sustento particulares, comúnmente forma la columna vertebral de los sistemas comunitarios andinos y tiene una función clave en la producción y reconfirmación de los derechos y las reglas de agua. Aquí, los derechos y las obligaciones de cada miembro se derivan de los derechos y deberes colectivos. Además, los derechos de agua de cada familia dependen no solamente de la ejecución de sus obligaciones en el sistema de uso de agua, sino también en la ejecu- 
ción de otras tareas colectivas establecidas por la comunidad. Este hecho enraíza estos derechos, de maneras múltiples y complicadas, en otros componentes del fundamento normativo de las comunidades de agua andinas.

Aunque estén comúnmente ocultas de lo externo por el uso de estrategias miméticas de protección (adoptando apariencias institucionales formales) para resistir la interferencia estatal, estas fundaciones normativas de las comunidades de agua involucran patrones organizativos, reglas de operación y acuerdos claros con respecto a las tareas y los privilegios. El fundamento de la comunidad de agua entreteje dinámicamente el proceso de acceder y defender la fuente del agua; la definición de derechos, obligaciones y reglas de trabajo; las definiciones, valores, significados y símbolos locales, así como la relación de la comunidad humana con el agua y el ambiente natural (y a menudo el sobrenatural). Provee de un sentido de pertenencia mutua en el sentido de que los seres humanos colectivamente pertenecen a un sistema o fuente de agua particular, y viceversa.

Este fundamento colectivo es un espacio físico, cultural, sociolegal y político clave para maniobrar no sólo en el mundo del agua local, sino en los campos de batalla más amplios sobre el control del agua. Se concreta ya sea por medio de alianzas horizontales con otras organizaciones de base o de alianzas verticales con organizaciones regionales o internacionales e instituciones internacionales. De la mano con el fortalecimiento interno de sus cimientos locales, los grupos usuarios también necesitan lograr nexos a escala mayor para defender sus intereses relacionados con el recurso agua. A su vez, para la creación y efectividad de tales redes y alianzas estratégicas, dependen de sistemas de control del agua autoconfiados, conscientemente organizados y bien sostenidos, y con cimientos sólidos. Para esto, a pesar de las disputas y diferencias internas, son esenciales la unidad de cooperación, la coherencia y la autoridad legítima dentro de la organización usuaria del agua.

\section{Luchas por los derechos de agua}

Desde las Guerras del Agua abiertas hasta los enfrentamientos locales y encubiertos de las comunidades, casi todas las luchas por ese tema en las alturas andinas expresan que hay más en juego que sólo la distribución del poderoso recurso hídrico en sí mismo. Manifiestan que, además de la lucha por el material líquido en sí y su infraestructura, en un segundo nivel de 
contestación hay una disputa sobre las definiciones y los contenidos de los derechos de agua y las reglas de gestión. Luego, en un tercer nivel, tiene lugar la lucha sobre las facultades de toma de decisiones y la legitimidad de los sistemas normativos y sus autoridades; y, todavía en un cuarto nivel, se encuentran los discursos que defienden políticas, las construcciones normativas y las jerarquías hidráulicas. Los conflictos dejan en claro que los derechos de agua actuales no sólo dan acceso al líquido y a la infraestructura hidráulica, sino que también son relaciones de poder que definen el control sobre la toma de decisiones en la gestión del agua.

No debe sorprender, por lo tanto, que las políticas nacionales dominantes y el discurso político internacional que prevalecen en la era neoliberal estén buscando desarticular los derechos locales de agua y socavar los cimientos de las comunidades de agua y las identidades hidráulicas locales: un proceso de des-identificación con lo local, y de alineamiento con los intereses nacionales y externos. Pero las comunidades locales responden ante estos procesos de dominación política y homogeneización cultural. Luchan para rearticular activamente sus derechos de agua, y para defender y reconstruir su identidad hidráulica. Los derechos y las luchas por ellos y por la autoridad en los Andes no sólo ejemplifican la naturaleza inherentemente política del agua, sino que también están asociados de cerca con significados e identidades culturales. Así, sus luchas no deben ser estrechamente vistas como protestas contra los efectos de nuevas políticas hídricas, sino que requieren de una contextualización más amplia en términos históricos y sociales. Las luchas por el agua en los Andes también son luchas por la especificidad y la autonomía locales, por el derecho de autodefinición de la naturaleza de los problemas de agua, así como por la capacidad de decidir sobre la dirección de las soluciones. Por eso, las luchas son además una crítica de la propia racionalidad de las reformas, y activamente cuestionan sus pretensiones de neutralidad y objetividad. Desean mostrar que las leyes y decisiones políticas que se justifican sobre la base de la neutralidad y la eficiencia en la práctica real trabajan promoviendo una agenda política muy clara, y protestan contra la pretensión de que los modelos neoliberales estén fundamentados en algún tipo de ley natural. En consecuencia, las luchas no sólo demandan maneras alternativas para distribuir el agua, sino también nuevas maneras de pensar y hablar sobre el agua. ${ }^{43}$

43 Boelens and Zwarteveen, 2005, 735-758. 
Para contestar no sólo las injusticias de agua y las regulaciones expuestas por los poderes políticos coercitivos y visibles, sino también para desafiar los mecanismos invisibles del poder moderno disciplinante y normalizador, las comunidades tienen contraestrategias que, de forma igualmente intermitente, usan tácticas tanto visibles como invisibles. De manera alternada se vuelven hacia la resistencia abierta o el mimetismo, el disfraz, el anonimato y la identidad protegida; hacia las demandas legalmente expresadas y los arreglos localmente codificados; hacia la movilización de alto perfil y la creación de derechos y la defensa de la base de bajo perfil. Las luchas por la defensa de los derechos de agua se desarrollan y tienen lugar en el ámbito oculto del fundamento de la comunidad de agua y, en otros momentos estratégicos, emergen como manifestaciones públicas a escala nacional y hasta internacional.

\section{Resaca, resistencia y creatividad}

A pesar del predominio de la legislación de agua positivista, las políticas de agua universalistas y las estrategias de poder para disciplinar los repertorios locales de derechos de agua y las organizaciones usuarias, la existencia continuada de un pluralismo legal es en sí mismo un claro signo de que el proyecto normalizador no se ha completado ni se completará jamás. La diversidad de derechos de agua es una expresión de resistencia. El «espesor» de los arreglos normativos locales y su entretejido con todas las otras esferas del control del agua, físicas y metafísicas, organizativas y políticas, junto con una relativa autonomía, una informalidad y una inserción en las redes de comunidad y parentesco, hacen que los fundamentos de la comunidad no sólo protejan y sostengan una continuidad y una acción colectiva semiautónomas y permitan una resistencia reactiva y una protesta, sino que también constituyen formas de resistencia acti$v a$ a las políticas y las prácticas de la normalización. Los fundamentos de los derechos de una comunidad de agua son una resaca (en inglés: undertow: «una corriente bajo la superficie del agua que se mueve alejándose o a lo largo de la playa, mientras el agua de la superficie se mueve hacia la playa»). ${ }^{44}$ La base oculta o mimetizada de la no conformidad, las «resacas de los derechos de agua», por sí mismos (y aparte de las protestas

44 Webster's, Webster's New ..., 1994. 
comunitarias abiertas y públicas), son entidades poderosas y actos de resistencia.

Además, no sólo la existencia de una variedad de arreglos de derechos consuetudinarios forma una base importante de resistencia contra la usurpación, la dominación y las políticas disciplinarias. Es particularmente la creación constante, dinámica y subterránea de los derechos de agua consuetudinarios lo que opera como fuente básica de la defensa de los derechos de agua y como herramienta de resistencia. Es una estrategia consciente e inconsciente para mantener firmemente en las propias manos de la comunidad la generación de reglas y su puesta en vigor. Esa creación de reglas y derechos de agua refleja un proceso dialéctico, a través del cual la gente lucha y, al hacerlo, erige el mundo en el que vive. Los resultados, la forma y los contenidos de los sistemas de derechos de agua locales son un reflejo de esta lucha doméstica y hacia afuera.

Por último, como he argumentado, los derechos de agua son una relación social entre actores sociales; emergen de las estructuras de poder prevalecientes y también constituyen una relación de poder en sí mismos. Pero la lucha por los derechos de agua por parte de las comunidades locales es mucho más que sólo un intento de lograr poder-sobre, de incrementar el control sobre los recursos hídricos y sobre el comportamiento y acciones de los diferentes actores involucrados en la gestión del riego. También tiene que ver con el poder-para, poder-con y el poder-dentro:

El proceso de generar derechos de agua dentro de los sistemas y comunidades de uso de agua se refiere a la capacidad creativa (poder-para), y combina tres elementos básicos: la creación y recreación por los usuarios de esos derechos y sus contenidos específicos; la particular creación y adaptación de la infraestructura capaz de materializar los derechos de cada familia, y la creación y recreación de una adecuada organización para manejar el sistema y la fuente de agua.

Luego, el poder-con se muestra claramente a través de la lucha por mantener una organización sostenida, un cuerpo de derechos y obligaciones consensuados que vinculan a todas las familias de regantes, y de la acción colectiva, fundada no en una «solidaridad filantrópica» o en una «armonía andina», sino en la reciprocidad contractual y en la propiedad hidráulica colectiva, que vinculan los derechos de cada familia al derecho colectivo de la comunidad de agua. Al mismo tiempo, la unidad, la autonomía y los derechos colectivos, tomados en conjunto, pavimentan la vía para la batalla de legitimación de su sistema normativo, tanto en lo doméstico 
como hacia afuera. Así, el poder-con también se manifiesta en la movilización de redes multiescalares para defender o adquirir los derechos de agua en cantidad y calidad suficiente.

Resistir para poder crear, y crear para poder resistir: la historia pasada y presente de sus disputas por el acceso al agua, de su construcción y defensa de los sistemas normativos propios, y de su creación de sistemas de uso de agua entretejidos con las condiciones locales socioculturales, políticas y físicas, no ha resultado solamente en sistemas tecnológicos que, a través de organizaciones funcionales, llevan el agua a sus campos y hogares. Más que nada, estos procesos han conllevado una construcción social de complejos sistemas sociotécnicos que interactúan con contextos particulares fundamentados en las normas y capacidades específicas de sus creadores y defensores, con base en el poder colectivo y enraizados en las resacas, según el significado aquí de esta palabra ya comentado. Tales procesos de empoderamiento local de creación, adaptación, regeneración y diversificación de los derechos de agua fusionan la resistencia local con el cabildeo creativo y proveen de forma y sustancia a las identidades hidráulicas: su poder-dentro.

Recibido el 15 de marzo de 2010

Aceptado el 30 de mayo de 2011

\section{Bibliografía}

Arguedas, José María: «La novela y el problema de la expresión literaria en el Perú», reproducido en Yawar Fiesta, Buenos Aires, Editorial Losada, 1977 (1950), 165-174.

Assies, Willem: «The Limits of State Reform and Multiculturalism in Latin America», Boelens, R.; Getches, D., and Guevara, A. (eds.): Out of the Mainstream. Water rights, politics and identity, London/ Washington, Earthscan, 2010, 57-74.

Bakker, Karen: Privatizing Water: Governance Failure and the World's Urban Water Crisis, Ithaca, NY, Cornell University Press, 2009.

Bebbington, Anthony; Bebbington, Denise Humphreys, and Bury, Jeff: «Federating and defending: Water, territory and extraction in the Andes», Boelens, Getches and Guevara (eds.): Out of the Mainstream, London/ Washington, Earthscan, 2010, 307-327. 
Boelens, Rutgerd: «Water rights arenas in the Andes: Upscaling the defence networks to localize water control», Water Alternatives, 1, 1, Montpellier, 2008, 48-65.

Boelens, «'Aguas diversas'. Derechos de agua y pluralidad legal en las comunidades andinas», Anuario de Estudios Americanos (Anu.est.am), 66, 2, Sevilla, julio-diciembre 2009a, 23-55.

Boelens, 'The Politics of Disciplining Water Rights», Development and Change, 40 (2), La Haya, 2009b, 307-331.

Boelens, Rutgerd y Gelles, Paul H.: 'Cultural politics, communal resistance and identity in Andean irrigation development', Bulletin of Latin American Research, 24, 3, Oxford, 2005, 311-327.

Boelens, Rutgerd y Zwarteveen, Margreet: «Prices and politics in Andean water reforms», Development and Change, 36, 4, La Haya, 2005, 735-758.

Boelens, Getches and Guevara (eds.): Out of the Mainstream. Water rights, politics and identity, London/ Washington DC, Earthscan, 2010.

Budds, Jessica: «Water Rights, Mining and Indigenous Groups in Chile's Atacama», ibidem, 197-212.

Bustamante, Rocio; Peredo, Elizabeth and Udatea, María Esther: «Women and the 'Water War' in the Cochabamba valleys», Bennett, V.; Dávila-Poblete, S., and Rico, M.N. (eds.): Opposing Currents, Pittsburgh, University of Pittsburgh Press. 2005, 72-90.

Cáceres, Efraín: El Juicio del Agua-Unu Huishu. Simbolismo y significado ecológico del agua en mitos andinos, Quito, Abya-Yala, 2002.

Castro, Jose Esteban: «Presentación. Dossier: Agua y desigualdad en América Latina», Anu.esu.am, 66, 2, julio-diciembre 2009, 15-22.

CONAIE: Propuesta Ley de Aguas, Quito, CONAIE, 1996.

Cremers, Leontien; Ooijevaar, Marjolein, and Boelens, Rutgerd: «Institutional reform in the Andean irrigation sector: Enabling policies for strengthening local rights and water management», Natural Resources Forum, 29, Oxford, 2005, 37-50.

Crespo Flores, Carlos O.: «Privatización del agua y racismo ambiental en ciudades segregadas. La empresa Aguas del Illimani en las ciudades de La Paz y El Alto (1997-2005)», Anu.est.am, 66, 2, julio-diciembre 2009, 105-122.

Dávalos, Pablo: El movimiento indígena ecuatoriano en la trampa del liberalismo, Quito, CONAIE, 2007.

Foucault, Michel: «Technologies of the Self». Martin, L.H.; Gutman, H. and Hutton, P. (eds.): Technologies of the Self: A Seminar with Michel Foucault, 16-49. London, Tavistock, 1988 (1982).

Foucault, Discipline and punish. The birth of the prison. New York, Vintage Books, 1995 (1975). 
Gelles, Paul H.: «Competing cultural logics: State and 'indigenous' models in conflict», Boelens, R. and Dávila, G.(eds.): Searching for equity, Assen, Países Bajos, Van Gorcum, 1998, 256-267.

Gelles, Water and power in highland Peru: The cultural politics of irrigation and development, New Brunswick, NJ, Rutgers University Press, 2000.

Granadino, Cecilia and Jara Jiménez, Cronwell: Las ranas embajadoras de la lluvia y otros relatos, Lima, Minka, 1996.

Greslou, François: Visión andina y usos campesinos del agua, Lima, PRATEC, 1989.

Guevara, Armando: «Official water law versus indigenous and peasant rights in Peru», Boelens, R.; Chiba, M. and Nakashima, D. (eds.): Water and Indigenous Peoples, Paris, UNESCO, 2006, 126-143.

Laruta, Hugo Carlos; Bustamante, Rocio et al.: Derechos y Gestión del Agua en Ancoraimes, Bolivia. La Paz, CIPCA / WALIR, Plural Editores, 2007.

Long, Norman; Douwe van der Ploeg, Jan; Curtin, Cris and Box, Lou: The commoditization debate: labor process, strategy and social network, Wageningen, Países Bajos, Wageningen University, 1986.

Mayer, Enrique: The articulated peasant. Household economies in the Andes, Boulder and Oxford, Westview Press, 2002.

Moffat, Linda; Geadah, Yolanda, and Stuart, Rieky: Two halves make a whole. Balancing gender relations in development, Ottawa, Canadian Council for International Co-operation, 1991.

Oré, María Teresa: Agua, bien común y usos privados. Riego, Estado y conflictos en La Achirana del Inca, Lima, WALIR/ Wageningen University and PUCP, 2005.

Palacios, Paulina: «Between customs and the establishment of juridical pluralism», en Boelens, Chiba, and Nakashima (eds.): Water and Indigenous Peoples, Paris, UNESCO, 2006, 160-173.

Peredo, Elizabeth: Las mujeres del Valle de Cochabamba: agua, privatización y conflicto, Cochabamba, Fundación Solón, 2003.

Perreault, Tom: «Custom and contradiction: rural water governance and the politics of usos y costumbres in Bolivia's irrigators' movement», Annals of the Association of American Geographers, 98, 4, New York, 2008, 834-854.

Romero Toledo, Hugo; Romero Aravena, Hugo y Toledo Olivares, Ximena: «Agua, Poder y Discursos: Conflictos Socio-territoriales por la construcción de centrales hidroeléctricas en la Patagonia Chilena», Anu.est.am, 66, 2, julio-diciembre de 2009, 81-103.

Scott, James: Domination and the Arts of Resistance. Hidden Transcripts. New Haven and London, Yale University Press, 1990. 
Skar, Harald: La gente del valle caliente. Dualidad y reforma agraria entre los runakuna de la sierra peruana, Lima, Fondo Editorial, Universidad Católica del Perú, 1997.

Swyngedouw, Eric: «'Globalisation or 'Glocalisation'? Networks, territories and rescaling», Cambridge Review of International Affairs, 17, 1, Cambridge, 2004, 25-48.

Vos, Hugo de; Boelens, Rutgerd, and Bustamante, Rocio: «Formal law and local water control in the Andean region: a fiercely contested field», International Journal of Water Resources Development, 22, 1, London, 2006, 37-48

Webster's: Webster's New Encyclopedic Dictionary, Cologne, Konemann, 1994. 